\title{
Determination of Bond Performance Characteristics of Steel Reinforcement Pull-Out and Splitting Failure in Reinforced Concrete Members
}

\author{
Overo Kenneth Ejukone mu1 ${ }^{1}$, Charles Kennedy ${ }^{2}$, Arube Goodne ws Emuakpo ${ }^{3}$ \\ ${ }^{1,3}$ Faculty of Engineering, Department of Civil Engineering, Niger Delta University, \\ Wilberforce Island, Bayelsa State \\ ${ }^{2}$ Department of Civil Engineering, Faculty of Engineering, Rivers State University, Port \\ Harcourt - Rivers State, Nigeria \\ Authors E-mail: ${ }^{1}$ kennethovero@gmail.com, ${ }^{3}$ ken_charl@yahoo.co.uk, \\ 2arube.goodnews@gmail.com,
}

The interaction between concrete and reinforcing steel is expected to be cordially perfect to enable the exhibition of maximum bonding in the surrounding concrete structures. The experimental work evaluated the representation of the ideal coastal marine region of high salinity and the potential application of raphia hookeri exudate/resin extract as inhibitory material coated on reinforcing steel, embedded in concrete in curbing the scourge and menace of corrosion effect on reinforced concrete structures exposed or built within the severe and harsh region. Comparatively, an evaluation from the data for 12 controlled samples pooled in a freshwater tank, 12 uncoated and 12 coated pooled in $5 \%$ sodium chloride $(\mathrm{NaCl})$ aqueous solutions all for 360 days. The results of average and percentile values for failure bo nd loads, bond strength, maximum slip, cross-sectional reduction/increase, and weight loss/gain obtained showed that the failure bond load for controlled and coated maintained a close range of values while corroded members yielded on lower load application, similar factors are on bond strength and maximum slip. On the mechanical properties of the reinforcing steel, the effect of corrosion on the reinforcing steel exhibited cross-section reduction on the diameter of the bar as compared to nominal diameter before the test, weight loss also notice while and coated members possess cross-sectional area increased, diameter increase and weight increase as compared to nominal rebar, these increased resulting from the coating materials varying thicknesses. It can be concluded that the studied exudate/resin showed the potency of inhibitory characteristics against corrosion attack and can be used as an inhibitor to corrosion. Key Words: Corrosion, Corrosion inhibitors, Pull-out Bond Strength, Concrete and Steel Reinforcement

\section{INTRODUCTION}

The effect of corrosion on reinforced concrete structures has been greatly influenced by the reduction of tensile strength transfer from concrete to reinforcing steel, bonding interaction between steel reinforcements - the global phenomenon of concrete and structural behavior has been demonstrated by many experimental studies ([1], [2], [3], [4]). Bond strength originates mainly from the weak chemical bonds between steel and hardened cement, but this resistance breaks with very little pressure. Once the slip occurs, friction contributes to bonding. In plain reinforcing steel bars, friction is a major component of strength. Reinforcing the ribbed steel bars and under a growing slip bond mainly depends on the bearing or mechanical interlock between the ribs and the surrounding concrete on the surface. At this stage, the reinforcement bar produces bursting forces that divide the surrounding 
concrete. Corrosion can cause initial cracking, which creates tensile stress in the steel reinforcement environments in concrete, reduces the overall strength and rigidity of the concrete structures [5].

[6] Studied and evaluated the effect of corrosion of the bond between the reinforcing steel surface and the concrete interface of corroded and exudates inhibited reinforcement with resins. The test samples were subjected to bond strengths that are complex and deductive, and the results obtained showed failure load, bond strength, and high rate of penetration rates. Overall results have shown good bonding and efficiency in the use of ficus glumosa resins/exudates as protective material against corrosion.

[7] Investigated the underlying details for the reduction of service life, integrity, and strength of reinforced concrete structures in the marine environment. Comparable results showed bond yield failure, bond strength and maximum slipping decreased. The overall results showed a low percentage and a large percentage of merged members. This justifies the effect of corrosion on the strength of the composite and bonded joints.

[8] Investigated the effect of resin/exudates on the corrosion resistance of reinforced concrete cubes. The obtained results revealed that the failure bond load, bond strength, and the maximum slip of the coated resin cubes were high. Similar results were obtained with higher resin-coated and non-corroded steel reinforcement.

[10] investigated the effects of deformed and coated reinforcement on the stress generated from the bond separation of non-corrode, corroded, and resins/exudates paste coated members. The results showed that the corrosion rates increased compared with the coated models, which resulted in adhesion conditions from the resins/exudates to strengthen the reinforcement and also served as a protective coat against corrosion.

[11] Examined the bond strength of non-corroded, corroded, and exudates/resin coated samples of reinforced concrete structures of $150 \mathrm{~mm} \times 150 \mathrm{~mm} \times 150 \mathrm{~mm}$ standard cubes, immersed in a corrosive medium for 150 days, with non-coated corroded and coated. Collective results demonstrated that corroded specimens with weak maximum slip during split separation testing and high failure load and lower bond strength. Non-corroded and exudates/resin-coated models have high bond strength and low failure load. Exudate/resin designs show high protective properties against corrosion effects, thereby acting as inhibitors. Exudates/resins coated specimens exhibit high-performance resistance properties for bond strength, and maximum slip with minimal failure compared to corroded specimens.

[12] Examined the effect of corrosion inhibitors on coated reinforcing steel under accelerated process examination of failure bond strength of embedded steel for 150days. Comparatively, the results of the corroded samples are reduced and the exudates coated samples control samples increased. The overall results showed higher values of pull-out bond strength in the control and exudates/resin coated members as against corroded samples.

[13] Studied the application of environmentally-friendly corrosion inhibitors of exudates/resins from a natural source to reinforcing steel bars of $150 \mu \mathrm{m}, 300 \mu \mathrm{m}$, and $450 \mu \mathrm{m}$ thickness are coated and embedded in concrete cubes, cured in fast corrosive media, and investigated pull-out bond strength parameters against non-coated ones. Relatively, the results of the corroded specimens' decreased while controlled, and cola accuminata exudates/ resins increased in steel bar coated samples. Overall results show that natural exudates/resins be explored as inhibitors for corrosion effects in steel reinforcement in concrete construction in areas where chloride is expected.

[14]) Investigated the bond strength between the reduction of concrete and reinforcement capacity due to the effect of the corrosion on the steel reinforcement resulting from saltwater presence. The application of exudates/resin extract of artocarpus altilis was used to enhance reinforcing steel coating with $150 \mu \mathrm{m}, 300 \mu \mathrm{m}$, and $450 \mu \mathrm{m}$ thickness, with an embedment of non-coated and coated reinforcing steel into concrete cubes and saturated in sodium chloride 
for 150 days to assess the corrosion effects. The overall results showed high values of bond strength from coated samples over non-coated samples, these results showed the negative effects of corrosion attack on the mechanical properties of reinforcing steel.

[15] Explored the impact of olibanum exudates/resins in reinforcing steel corrosion in coastal zones under the influence of saltwater on concrete structures. The non-coated and exudates / resin-coated steel were embedded in concrete cubes and pooled in a corrosive medium to evaluate the effects of corrosion. Tests have shown that the values of non-coated samples have deteriorated due to the reduced corrosion attack. The average percentage bond strength load is $33.13 \%$ and the coating members are $45.66 \%$ and $71.84 \%$ compared to the control differential. The mean maximum slip values were $0.083 \mathrm{~mm}$ and average $33.87 \%$ and $75.30 \%$, respectively, compared to control and finish $-25.30 \%$. Experimental results show that reduced samples have lower bond strength and higher failure bond load and lower maximum slip, while exudates/resins coated samples have lower test samples and higher percentage values compared to corrosive samples.

[16] Examined the effect of corrosion attack on Acacia Senegal exudates/resin paste coated non-coated reinforcing steel and submerged in an aggressive medium for 178 days. The obtained results showed that non-coated members failed in bond loading value against controlled and exudates/resins coated members. In comparison, the values of the corroded specimens are reduced but controlled and the exudates/resins coated members are increased, indicating the potential of acacia Senegalese.

[17]Examined the characteristics of bond strength between steel and reinforced concrete structures using corroded and khaya senegalensis inhibited reinforcing steel members, embedded in concrete members, and exposed to corrosive media. The results of the failure bond loads showed a difference of $-43.62 \%$ and $77.37 \%$ and $79.67 \%$ for corrosive and coated exudates/resin members, respectively. The reduced average percentage bond strength load ranges from $57.06 \%$ to $36.33 \%$ and $106.57 \%$ in stained and coated samples. The obtained results clearly show that corrosive bond loads are higher for the corroded than for the exudates / adhesive coating members of the corrosion sample. The cohesive strength of corroded and coated specimens showed a greater affinity for coated compared to corroded specimens.

\section{MATERIALS AND METHODS FOR EXPERINMENT}

This research involves the direct application of exudates/resins tapped from plants known as inhibitors, which are coated in steel reinforcement and laboratory tested experimentally. The test specimen reflects severe acid conditions that represented sea salt concentration conditions in reinforced concrete, cubes with embedded reinforcing steel were wholly submerged and specimens maintained in pooling tank for corrosion accelerated process. Samples were designed with 36 numbers of reinforced concrete cubes of $150 \mathrm{~mm} \times 150 \mathrm{~mm}$ $\times 150 \mathrm{~mm}$, with a single strip of $12 \mathrm{~mm}$ diameter embedded centrally for pullout bond testing for controlled, non-coated, and coated samples and all immersed in sodium chloride $(\mathrm{NaCl})$ for 360 days after initial 28 days curing process. Samples of acidic media were monthly renewed and samples monitored for effective performance.

\section{Aggregates}

Excellent wholesale and coarse aggregate purchased. Both met the requirements of [18] Cement

Portland lime cement grade 42.5 is the most common type of cement in the Nigerian market. It was used for all concrete mixtures in this trial. Meets the requirements of Cement [19] 


\section{Water}

The water samples were clean and free from contaminants. Freshwater was obtained from the tap at the Department of Civil Engineering Laboratory, Kenule Beason Polytechnic, Bori, Rivers State. Water [20] met the requirements

\section{Structural steel reinforce ment}

Reinforcements are obtained directly from the market at Port Harcourt, [21]

\section{Corrosion Inhibitors (Resins / Exudates) Raphia hookeri}

The gum exudates/resins were obtained from the cut sections of the raffia palm tree stem inflorescent part from Ubeta forest in Ahoada - West Local Government Area of Rivers State.

\section{Experimental procedures}

Corrosion acceleration test was performed on high yielding steel (reinforcement) with a diameter of $12 \mathrm{~mm}$ and a length of $650 \mathrm{~mm}$, the sample surface was treated with a wire brush and the samples were thoroughly cleaned with water, washed with acetone, and then coated raphia hookeri exudates/resins) pastes with varying thicknesses of $150 \mu \mathrm{m}, 300 \mu \mathrm{m}, 450 \mu \mathrm{m}$, and $600 \mu \mathrm{m}$ coatings before testing. The test cubes were cast with a $150 \mathrm{~mm} \times 150 \mathrm{~mm} \times 150$ $\mathrm{mm}$ metal mold and de-molded after 72 hours. Samples were treated at room temperature in tanks for an initial curing period of 28 days, followed by a rapid acceleration corrosion test and a trial procedure that allowed 360 days of regular monthly monitoring. For corrosionaccelerated specimens the cubes were taken approximately every 3 months at 90 days, 180 days, 270 days, and 360 days, and the gain of failure bond loads, binding strength, maximum slip, re-cross-sectional area reduction/increase, and weight loss/steel reinforcement.

\section{Accelerated corrosion setting and testing method}

In real and natural phenomena, the manifestation of corrosion effects on reinforcement embedded in concrete members is very slow and can take many years to achieve; But the laboratory accelerated process will take less and less time to unravel by the introduction of accelerated media representing the saltwater of the sea area. The samples were immersed in a $5 \% \mathrm{NaCl}$ solution for 360 days to test the surface and mechanical properties of the transitions and effects and to test both the unbound and the exudate/resin coated samples.

\section{Pull-out Bond Strength Test}

The tensile-bond strength test of concrete cubes was carried out on 12 samples each with a total of 36 samples of filtered water, non-coating and coated members, and subjected to a $50 \mathrm{kN}$ Universal Testing Machine according to BSEN12390-2. 36 cubes size $150 \mathrm{~mm} \times 150$ $\mathrm{mm} \times 150 \mathrm{~mm}$, embedded in the center of a single $12 \mathrm{~mm}$ diameter concrete cube.

\section{Tensile Strength of Reinforcing Bars}

Yield strength and Ultimate tensile strengths of $12 \mathrm{~mm}$ diameter, non-coated and coated reinforcing concrete cube members subjected to the universal testing machine for maximum failure to direct tension.

\section{EXPERIMENTAL RESULTS AND DISCUSSION}

The interaction between concrete and reinforcing steel is expected to be cordially perfect to enable the exhibition of maximum bonding in the surroundings concrete structures. The increase in deformed (rib) reinforcing bars and slip bonds mainly depends on the bearings or mechanical interlocks between the concrete around the ribs on the surface of the bar. The damaging effect from the attack by corrosion has rendered many structures unserviceable and designed life span shortened.

Experimental data presented in tables 3.2.3.2 and 3.3, summarized into tables 3.4 and 3.5 are test conducted on 36 concrete cubes samples of 12 controlled placed in freshwater for 360 days, 12 uncoated and 12 exudates/resin coated samples all embedded with reinforcing steel and immersed in 5\% sodium chloride $(\mathrm{NaCl})$ aqueous solution for 360 days and evaluated 
their performances with examinations, monitoring, checking and testing intervals of 3 months at 90 days, 180 days, 270 days and 360 days. Indeed, the manifestation of corrosion is a longterm process which takes decades for full functionality, but the artificially introduction of sodium chloride triggers the manifestation and occurrence of corrosion with lesser time. The experimental work represented the ideal coastal marine region of high salinity and the potential application for of raphia hookeri exudate / resin extract as inhibitory material in curbing the scourge and menace of corrosion effect on reinforced concrete structure exposed or built within such severe and harsh region.

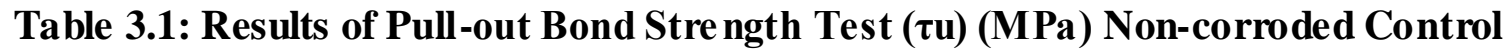
Cube Specimens

\begin{tabular}{|c|c|c|c|c|c|c|c|c|c|c|c|c|c|c|}
\hline Sample Numbers & RHC & RHC1 & RHC2 & RHC3 & RHC4 & RHC5 & RHC6 & RHC7 & RHC8 & RHC9 & RHC10 & RHC11 \\
\hline & \multicolumn{7}{|c|}{ Time Interval after 28 days curing } \\
\hline $\begin{array}{c}\text { Sampling g and } \\
\text { Durations }\end{array}$ & \multicolumn{3}{|c|}{ Samples 1 (28 days) } & \multicolumn{2}{|c|}{ Samples 2 (28 Days) } & \multicolumn{2}{|c|}{ Samples 3 (28 Days) } & \multicolumn{2}{c|}{ Samples 4 (28 Days) } \\
\hline $\begin{array}{c}\text { Failure Bond Loads } \\
\text { (kN) }\end{array}$ & 28.382 & 27.904 & 27.927 & 29.007 & 27.732 & 28.740 & 28.437 & 27.554 & 28.756 & 27.871 & 28.915 & 28.375 \\
\hline Bond strength (MPa) & 8.544 & 8.777 & 8.077 & 7.863 & 8.577 & 8.894 & 9.232 & 9.608 & 8.784 & 8.804 & 9.724 & 9.875 \\
\hline Max. slip (mm) & 0.102 & 0.107 & 0.102 & 0.102 & 0.117 & 1.000 & 0.104 & 0.105 & 0.109 & 0.117 & 0.120 & 0.105 \\
\hline $\begin{array}{c}\text { Nominal Rebar } \\
\text { Diameter }\end{array}$ & 12.000 & 12.000 & 12.000 & 12.000 & 12.000 & 12.000 & 12.000 & 12.000 & 12.000 & 12.000 & 12.000 & 12.000 \\
\hline $\begin{array}{c}\text { Measured Rebar } \\
\text { Diameter Before } \\
\text { Test(mm) }\end{array}$ & 11.998 & 11.989 & 11.999 & 11.998 & 11.990 & 12.008 & 11.995 & 11.984 & 11.996 & 11.997 & 11.986 & 11.996 \\
\hline $\begin{array}{c}\text { Rebar Diameter- at 28 } \\
\text { Days Nominal(mm) }\end{array}$ & 11.998 & 11.989 & 11.999 & 11.998 & 11.990 & 12.008 & 11.995 & 11.984 & 11.996 & 11.997 & 11.986 & 11.996 \\
\hline $\begin{array}{c}\text { Cross- section Area } \\
\text { Reduction/Increase } \\
\text { (Diameter, mm) }\end{array}$ & 0.000 & 0.000 & 0.000 & 0.000 & 0.000 & 0.000 & 0.000 & 0.000 & 0.000 & 0.000 & 0.000 & 0.000 \\
\hline $\begin{array}{c}\text { Rebar Weights- } \\
\text { Before Test (Kg) }\end{array}$ & 0.586 & 0.583 & 0.588 & 0.582 & 0.585 & 0.585 & 0.584 & 0.591 & 0.582 & 0.583 & 0.588 & 0.584 \\
\hline $\begin{array}{c}\text { Rebar Weights- at 28 } \\
\text { Days Nominal (Kg) }\end{array}$ & 0.586 & 0.583 & 0.588 & 0.582 & 0.585 & 0.585 & 0.584 & 0.591 & 0.582 & 0.583 & 0.588 & 0.584 \\
\hline $\begin{array}{c}\text { Weight Loss /Gain of } \\
\text { Steel (Kg) }\end{array}$ & 0.000 & 0.000 & 0.000 & 0.000 & 0.000 & 0.000 & 0.000 & 0.000 & 0.000 & 0.000 & 0.000 & 0.000 \\
\hline
\end{tabular}

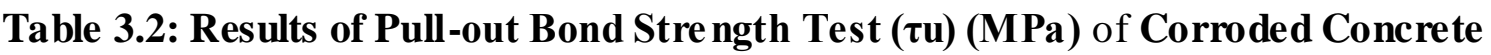
Cube Specimens

\begin{tabular}{|c|c|c|c|c|c|c|c|c|c|c|c|c|}
\hline $\begin{array}{c}\text { Samplin g and } \\
\text { Durations }\end{array}$ & \multicolumn{3}{|c|}{ Samples 1 (90 days) } & \multicolumn{3}{|c|}{ Samples 2 (180 Days) } & \multicolumn{2}{c|}{ Samples 3 (270 Days) } & \multicolumn{2}{c|}{ Samples 4 (360 Days) } \\
\hline $\begin{array}{c}\text { Failure Bond Loads } \\
\text { (kN) }\end{array}$ & 15.922 & 15.235 & 15.525 & 14.967 & 14.215 & 15.083 & 14.662 & 14.970 & 14.668 & 15.903 & 14.782 & 15.516 \\
\hline $\begin{array}{c}\text { Bond strength } \\
\text { (MPa) }\end{array}$ & 7.187 & 7.197 & 6.961 & 7.184 & 6.950 & 6.923 & 6.721 & 7.410 & 6.385 & 6.873 & 0.721 & 7.033 \\
\hline Max. slip (mm) & 0.082 & 0.085 & 0.086 & 0.095 & 0.085 & 0.089 & 0.088 & 0.078 & 0.084 & 0.085 & 0.086 & 0.077 \\
\hline $\begin{array}{c}\text { Nominal Rebar } \\
\text { Diameter }\end{array}$ & 12.000 & 12.000 & 12.000 & 12.000 & 12.000 & 12.000 & 12.000 & 12.000 & 12.000 & 12.000 & 12.000 & 12.000 \\
\hline $\begin{array}{c}\text { Measured Rebar } \\
\text { Diameter Before } \\
\text { Test(mm) }\end{array}$ & 11.933 & 11.924 & 11.934 & 11.933 & 11.924 & 11.943 & 11.934 & 11.923 & 11.933 & 11.930 & 11.924 & 11.934 \\
\hline $\begin{array}{c}\text { Rebar Diameter- } \\
\text { After } \\
\text { Corrosion(mm) }\end{array}$ & 11.884 & 11.875 & 11.885 & 11.884 & 11.875 & 11.894 & 11.885 & 11.874 & 11.884 & 11.881 & 11.875 & 11.885 \\
\hline $\begin{array}{c}\text { Cross- section Area } \\
\text { Reduction/Increase } \\
\text { (Diameter, mm) }\end{array}$ & 0.049 & 0.049 & 0.049 & 0.049 & 0.049 & 0.049 & 0.049 & 0.049 & 0.049 & 0.049 & 0.049 & 0.049 \\
\hline $\begin{array}{c}\text { Rebar Weights- } \\
\text { Before Test(Kg) }\end{array}$ & 0.559 & 0.560 & 0.560 & 0.558 & 0.561 & 0.561 & 0.561 & 0.561 & 0.560 & 0.562 & 0.559 & 0.559 \\
\hline $\begin{array}{c}\text { Rebar Weights- } \\
\text { After Corrosion } \\
\text { (Kg) }\end{array}$ & 0.507 & 0.513 & 0.507 & 0.509 & 0.509 & 0.508 & 0.516 & 0.506 & 0.507 & 0.513 & 0.508 & 0.510 \\
\hline $\begin{array}{c}\text { Weight Loss /Gain } \\
\text { of Steel (Kg) }\end{array}$ & 0.052 & 0.047 & 0.053 & 0.049 & 0.052 & 0.052 & 0.045 & 0.055 & 0.053 & 0.050 & 0.051 & 0.049 \\
\hline
\end{tabular}


DOI : https://dx.doi.org/10.26808/rs.re.v5i4.01

International Journal of Research in Eng ineering \& Science

ISSN:(P) 2572-4274 (O) 2572-4304

Available online on http://rspublication.com/IJRES/IJRE.html

volu me 5 Issue 4 Jul- Aug 2021

Table 3.3: Results of Pull-out Bond Stre ngth Test ( $\tau$ ) (MPa) of Raphia hookeri Exudate / Resin (Steel Bar Coated Specimen)

\begin{tabular}{|c|c|c|c|c|c|c|c|c|c|c|c|c|}
\hline Sumpling and & \multicolumn{3}{|c|}{ Samples 1 (90 days) } & \multicolumn{3}{|c|}{ Samples 2 (180 Days) } & \multicolumn{3}{|c|}{ Samples 3 (270 Days) } & \multicolumn{3}{|c|}{ Samples 4 (360 Days) } \\
\hline Sample & $150 \mu \mathrm{m}$ & $\begin{array}{l}\text { (Exudat } \\
\text { coated }\end{array}$ & Resin) & $300 \mu m$ & $\begin{array}{l}\text { (Exudat } \\
\text { coated }\end{array}$ & Resin) & $450 \mu \mathrm{m}$ & $\begin{array}{l}\text { (Exudat } \\
\text { coated }\end{array}$ & Resin) & $600 \mu \mathrm{m}$ & $\begin{array}{l}\text { (Exudat } \\
\text { coated }\end{array}$ & Resin) \\
\hline $\begin{array}{l}\text { Failure Bond Loads } \\
\text { (kN) }\end{array}$ & 27.438 & 25.349 & 25.913 & 26.509 & 27.324 & 27.025 & 27.549 & 27.366 & 27.431 & 29.242 & 28.366 & 28.568 \\
\hline Bond strength (MPa) & 9.484 & 10.376 & 8.874 & 9.804 & 10.177 & 11.100 & 11.194 & 10.524 & 10.558 & 11.264 & 10.575 & 11.122 \\
\hline Max. ship (mm) & 0.102 & 0.104 & 0.104 & 0.107 & 0.098 & 0.117 & 0.100 & 0.104 & 0.112 & 0.110 & 0.114 & 0.112 \\
\hline $\begin{array}{c}\text { Nominal Rebar } \\
\text { Diameter }\end{array}$ & 12.000 & 12.000 & 12.000 & 12.000 & 12.000 & 12.000 & 12.000 & 12.000 & 12.000 & 12.000 & 12.000 & 12.000 \\
\hline $\begin{array}{c}\text { Mcasured Rebar } \\
\text { Diamcter Before } \\
\text { Test(mm) }\end{array}$ & 11.961 & 11.953 & 11.962 & 11.962 & 11.952 & 11.972 & 11.962 & 11.951 & 11.962 & 11.959 & 11.952 & 11.963 \\
\hline $\begin{array}{c}\text { Rebar Diameter- } \\
\text { After } \\
\text { Corrosion(mm) }\end{array}$ & 12.009 & 12.001 & 12.010 & 12.010 & 12.000 & 12,020 & 12.010 & 11.999 & 12.010 & 12.0007 & 12.000 & 12.011 \\
\hline $\begin{array}{l}\text { Cross- scetion Arca } \\
\text { Reduction/Increase } \\
\text { (Diameter, mm) }\end{array}$ & 0.048 & 0.048 & 0.048 & 0.048 & 0,048 & 0.048 & 0.048 & 0,048 & 0.048 & 0.048 & 0.048 & 0.048 \\
\hline $\begin{array}{l}\text { Rebar Weights- } \\
\text { Before Test (Kg) }\end{array}$ & 0.592 & 0.593 & 0.593 & 0.591 & 0,503 & 0.593 & 0.594 & 0.594 & 0.593 & 0.595 & 0.592 & 0.592 \\
\hline $\begin{array}{c}\text { Rebar Weights- } \\
\text { After Corrosion (Kg) }\end{array}$ & 0.663 & 0.664 & 0.664 & 0.662 & 0.665 & 0.665 & 0.665 & 0,665 & 0.664 & 0.666 & 0.663 & 0.663 \\
\hline $\begin{array}{c}\text { Weight Loss /Gain } \\
\text { of Stcel (Kg) }\end{array}$ & 0.072 & 0.073 & 0.072 & 0.070 & 0.073 & 0.072 & 0.067 & 0.067 & 0.066 & 0.067 & 0.066 & 0.066 \\
\hline
\end{tabular}

Table 3.4: Results of Average Pull-out Bond Strength Test ( $\tau$ u) (MPa) of Control, Corroded and Exudate/ Resin Coated Steel Bar

\begin{tabular}{|c|c|c|c|c|c|c|c|c|c|c|c|c|}
\hline Sample & \multicolumn{4}{|c|}{$\begin{array}{c}\text { Non-Corroded Specimens } \\
\text { Average Values }\end{array}$} & \multicolumn{4}{|c|}{$\begin{array}{c}\text { Corroded Specimens Average } \\
\text { Values }\end{array}$} & \multicolumn{4}{|c|}{$\begin{array}{c}\text { Coated Specimens Average } \\
\text { Values of } 150 \mu \mathrm{m}, 300 \mu \mathrm{m}, \\
450 \mu \mathrm{m}, 6000 \mu \mathrm{m})\end{array}$} \\
\hline Failure load (KN) & 28.071 & 28.279 & 28.222 & 28.493 & 15.561 & 15.242 & 14.902 & 14.755 & 26.233 & 25.924 & 26.582 & 26.953 \\
\hline $\begin{array}{l}\text { Bond strength } \\
\text { (MPa) }\end{array}$ & 8.466 & 8.239 & 8.172 & 8.445 & 7.115 & 7.114 & 7.032 & 7.019 & 9.578 & 9.685 & 9.618 & 10.361 \\
\hline Max. slip (mm) & 0.104 & 0.104 & 0.107 & 0.406 & 0.084 & 0.088 & 0.089 & 0.090 & 0.103 & 0.105 & 0.103 & 0.107 \\
\hline $\begin{array}{l}\text { Nominal Rebar } \\
\text { Diameter }\end{array}$ & 12.000 & 12.000 & 12.000 & 12.000 & 12.000 & 12.000 & 12.000 & 12.000 & 12.000 & 12.000 & 12.000 & 12.000 \\
\hline $\begin{array}{l}\text { Measured Rebar } \\
\text { Diameter Before } \\
\text { Test(mm) }\end{array}$ & 11.996 & 11.996 & 11.996 & 11.999 & 11.930 & 11.930 & 11.930 & 11.933 & 11.959 & 11.959 & 11.959 & 11.962 \\
\hline $\begin{array}{l}\text { Rebar Diameter- } \\
\text { After } \\
\text { Corrosion(mm) }\end{array}$ & 11.996 & 11,996 & 11.996 & 11.999 & 11.881 & 11.881 & 11.881 & 11.884 & 12.011 & 12.011 & 12.011 & 12.014 \\
\hline $\begin{array}{l}\text { Cross- section Area } \\
\text { Reduction/Increase } \\
\text { (Diameter, mm) }\end{array}$ & 0.000 & 0.000 & 0.000 & 0.000 & 0.049 & 0.043 & 0.049 & 0.049 & 0.052 & 0.052 & 0.052 & 0.052 \\
\hline $\begin{array}{l}\text { Rebar Weights- } \\
\text { Before Test (Kg) }\end{array}$ & 0.586 & 0.584 & 0.585 & 0.584 & 0.560 & 0.559 & 0,560 & 0.560 & 0.592 & 0.592 & 0.592 & 0,592 \\
\hline $\begin{array}{l}\text { Rebar Weights- } \\
\text { After Comosion } \\
\text { (Kg) }\end{array}$ & 0.586 & 0.584 & 0.585 & 0.584 & 0.509 & 0.510 & 0.508 & 0.509 & 0.664 & 0.664 & 0.664 & 0.669 \\
\hline $\begin{array}{c}\text { Weight Loss /Gain } \\
\text { of Steel }(\mathrm{Kg})\end{array}$ & 0.000 & 0.000 & 0.000 & 0.000 & 0.051 & 0.050 & 0.051 & 0.056 & 0.072 & 0.075 & 0.072 & 0.075 \\
\hline
\end{tabular}




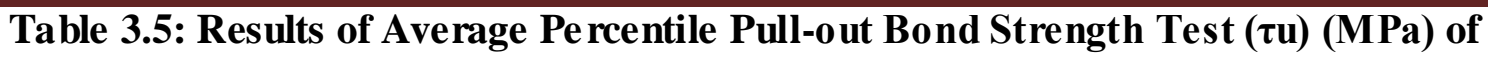
Control, Corroded and Exudate/ Resin Coated Steel Bar

\begin{tabular}{|c|c|c|c|c|c|c|c|c|c|c|c|c|}
\hline \multirow[b]{2}{*}{ Failure load (KN) } & \multicolumn{4}{|c|}{ Non-corroded Control Cube } & \multicolumn{4}{|c|}{ Corroded Cube Specimens } & \multicolumn{4}{|c|}{$\begin{array}{l}\text { Exudate / Resin steel bar coated } \\
\text { specimens. }\end{array}$} \\
\hline & 80.397 & 85.532 & 89.378 & 93.106 & 40,683 & 41.203 & 43.938 & $\overline{45.250}$ & 68.587 & 70.077 & 78.374 & 82.670 \\
\hline $\begin{array}{l}\text { Bond strength } \\
\text { (MPa) }\end{array}$ & 18.986 & 15,812 & 16.219 & 20.311 & 25,714 & 26.545 & 26.893 & 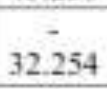 & 34.615 & 36.137 & 36.786 & 47.609 \\
\hline Max. slip (mm) & 23.315 & 17,306 & 20.744 & 33,995 & 18.662 & 15.879 & $14 \hat{201}$ & 16.678 & 22.944 & 18.876 & 16.551 & 20.016 \\
\hline $\begin{array}{l}\text { Nominal Rebar } \\
\text { Dianeter }\end{array}$ & 0.000 & 0.000 & 0.000 & 0.000 & 0.000 & 0.000 & 0.000 & 0.000 & 0.000 & 0.000 & 0.000 & 0.000 \\
\hline $\begin{array}{c}\text { Measured Rebar } \\
\text { Diameter Before } \\
\text { Test(mm) }\end{array}$ & 0.249 & 0.241 & 0.250 & 0.247 & 0,248 & 0.242 & 0.240 & 0.240 & 0.240 & 0.242 & 0.240 & 0.241 \\
\hline $\begin{array}{l}\text { Rebar Diameter- } \\
\text { After } \\
\text { Corrosion(mm) }\end{array}$ & 0.964 & 0.965 & 0.965 & 0.964 & $-1,079$ & $-1,081$ & -1.079 & -1.079 & 1.091 & 1.093 & 1.091 & 1.091 \\
\hline $\begin{array}{l}\text { Cross- section } \\
\text { Area } \\
\text { Reduction/Increase } \\
\text { (Diameter, mm) }\end{array}$ & 0.000 & 0.000 & 0.000 & 0.000 & -5.318 & -5.318 & -5.320 & -5.318 & 5.617 & 5.617 & 5.622 & 5.617 \\
\hline $\begin{array}{l}\text { Rebar Weights- } \\
\text { Before Test }(\mathrm{Kg})\end{array}$ & 4.599 & 4.477 & 4.561 & 4.303 & 4.479 & 5.482 & 5.480 & 5.479 & 5.797 & 5.800 & 5.798 & 5.797 \\
\hline $\begin{array}{l}\text { Rebar Weights- } \\
\text { After Corrosion } \\
\text { (Kg) }\end{array}$ & 15.014 & 14.666 & 15.091 & 14.754 & 23.313 & $\begin{array}{c}- \\
23.177\end{array}$ & 23,395 & 23.357 & 30.400 & 30.169 & 30.539 & 30.474 \\
\hline $\begin{array}{l}\text { Weight Loss /Gain } \\
\text { of Steel }(\mathrm{Kg})\end{array}$ & 0.000 & 0.000 & 0.000 & 0.000 & 29.688 & 30.608 & 28.534 & 28.974 & 42.223 & 44.108 & 39.927 & 40.794 \\
\hline
\end{tabular}

\section{Failure load, Bond Strength, and Maximum slip}

Bar cladding also reduces the relative area of the ribs and reduces the transmission of forces from the concrete to the reinforcement strip due to reduced mechanical interactions. The reinforcement layer is a weak layer between the reinforcement and the surrounding concrete. The shear deformation of the layer increases the slip between the concrete and the reinforcement. Therefore, the epoxy reinforcing layer affects the bond strength and thus the usability of the reinforced concrete structure.

The detrimental effects of this coating can be minimized by (1) providing a longer joint length; (2) large reinforcement covers, and (3) side closures over the joint area as reported by the [22]. Increasing the reinforcement cover can be effective before the concrete cracks. Data presented of failure bond load, bond strength and maximum slip of shown in tables $3.1,3.2$ and 3.3 and collapsed into 3.4 and 3.5 are data obtained from experimental tested conducted on 36 averagely and randomly selected samples of concrete cube of controlled, uncoated (corroded) and coated. The pullout bond test was used to examined the performances of these samples in highly and severe harsh environment for 360 days and on documentative and test intervals of 3 months and ascertained the morphological surface changes at 90 days, 180 days, 270 days and 360 days, also studied the effects of coating thicknesses of the studied exudates / resin. The samples were pressure tested to failure in Instron Universal Testing Machine of 50kN and results digitally and systematically recorded.

The obtained computed data are summarized from tables 3.1-3.3 into 3.4 -3.5 for failure bond load with the average and percentile minimum and maximum values for evaluations are controlled $28.071 \mathrm{kN}$ to $28.493 \mathrm{kN}(80.397 \%$ to $93.106 \%$ ), uncoated (corroded) are $14.755 \mathrm{kN}$ and $15.561 \mathrm{kN}(-45.256 \%$ and $-40.683 \%)$ and coated are $26.233 \mathrm{kN}$ and $26.953 \mathrm{kN}(68.587 \%$ and $82.67 \%$. 
Bond strength results for controlled are $8.172 \mathrm{MPa}$ and $8.466 \mathrm{MPa}(18.986 \%$ and $20.311 \%)$ corroded are 7.032MPa and 7.115MPa $(-32.254 \%$ and $-25.714 \%)$ and coated are $9.578 \mathrm{MPa}$ and $10.361 \mathrm{MPa}(34.615 \%$ and $47.609 \%)$, results of maximum slip are controlled are $0.104 \mathrm{~mm}$ and $0.107 \mathrm{~mm}(20.744 \%$ and $33.995 \%)$, uncoated corroded are $0.084 \mathrm{~mm}$ and $0.090 \mathrm{~mm} \quad(-18.662 \%$ and $-14.201 \%)$ and coated $0.103 \mathrm{~mm} 0.107 \mathrm{~mm}(16.551 \%$ and $22.944 \%$ ). From the result presented in tables 3.4 of average values derived from tables 3.1 , 3.2 and 3.3 and summarized into 3.5 from 3.4 to percentile values difference, the failure bond load are corroded $-40.683 \%$ against $82.67 \%$ and $82.67 \%$ coated and controlled respectively, this results showed an indications of low failure loads recorded in corroded, decreased values resulted from the attacks from corrosion that has affected the mechanical properties of reinforcing steel. Similarly, the bond strength maximum corroded values are corroded and maximum slip of corroded samples are $-25.714 \%$ ) against $20.311 \%$ and $47.609 \%$ controlled and coated. This result showed decreased and low bond strength as compared to both controlled and coated samples, attributing highest strength in coated due to the sticky and gummy characteristics exhibited exudates/resin. The maximum slip values for corroded are 14.201 , coated $33.995 \%$ and controlled $22.944 \%$. and with the indications that the higher percentile values in controlled and coated resulted to no loss of mechanical properties of reinforcing steel as against corroded with now ribs due to corrosion attack.

The result showed indications of the effect of corrosion on the failure bond load, bond strength and maximum slip as stated in the studies of ([9], [13],[18], [15]). Corrosion presence reduced the performance of corroded materials there by reducing mechanical characteristics of surface modification which affects bonding and the interaction between concrete and reinforcing steel.

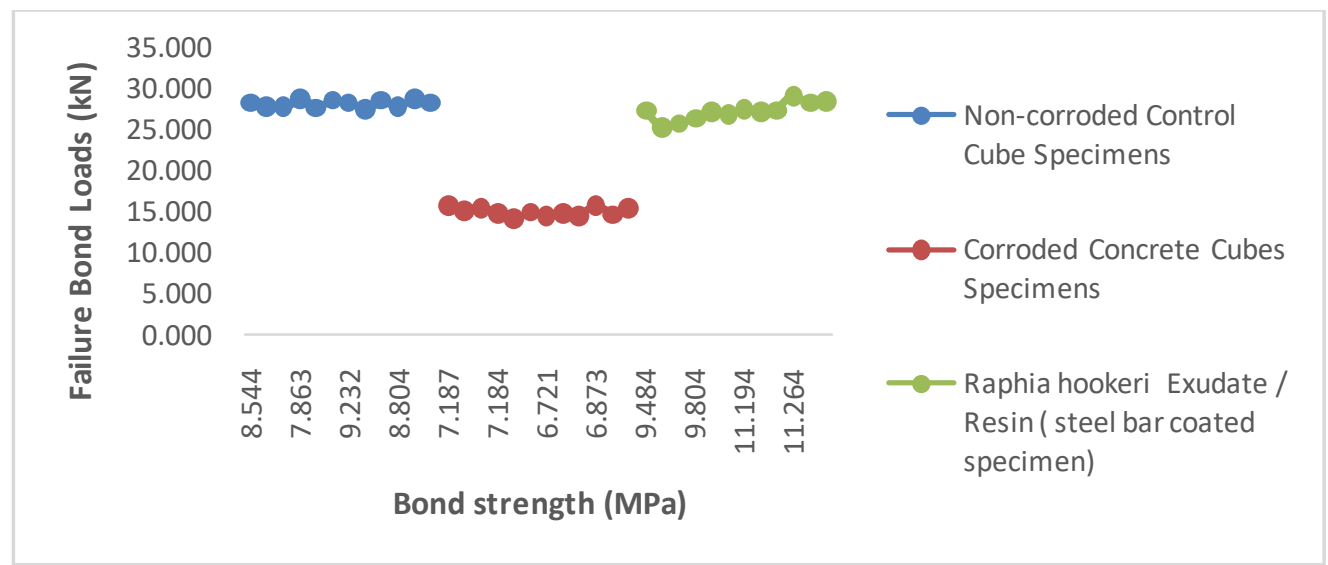

Figure 1: Failure Bond loads versus Bond Strengths

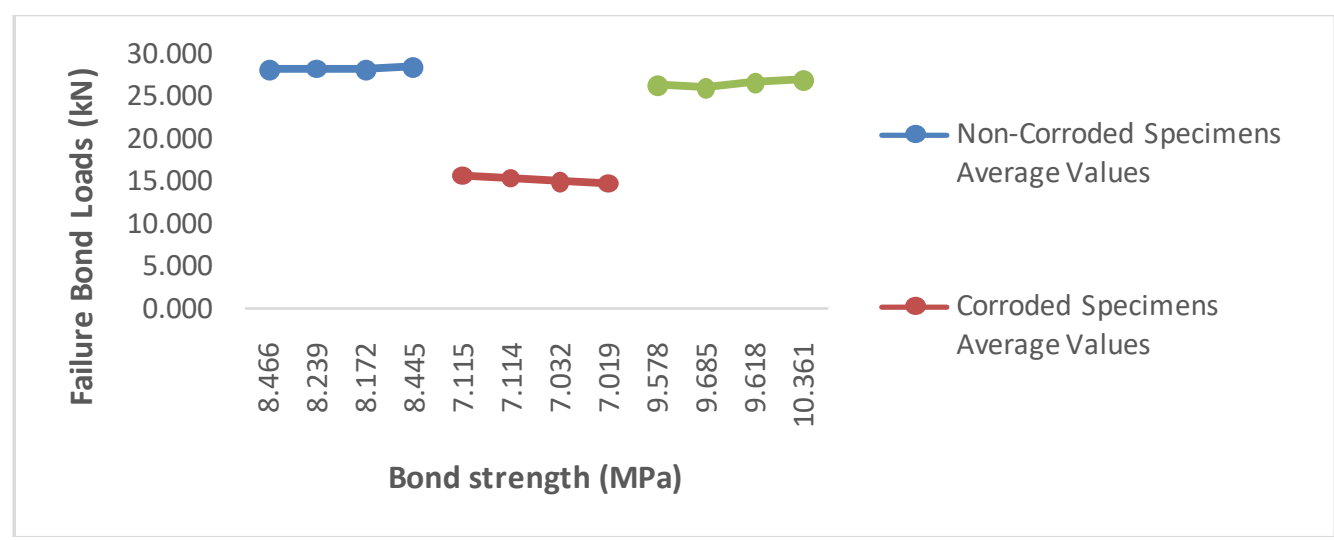

Figure 1a: Average Failure Bond loads versus Bond Strengths 


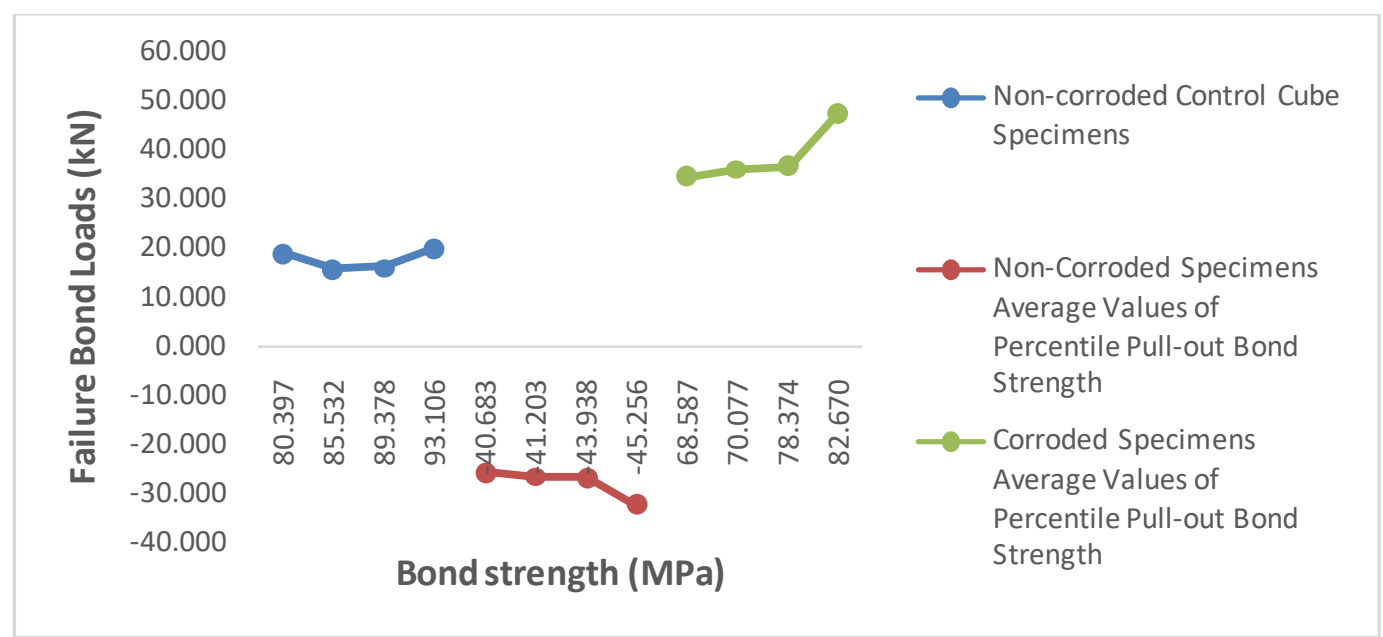

Figure 1b: Average Percentile Failure Bond loads versus Bond Strengths

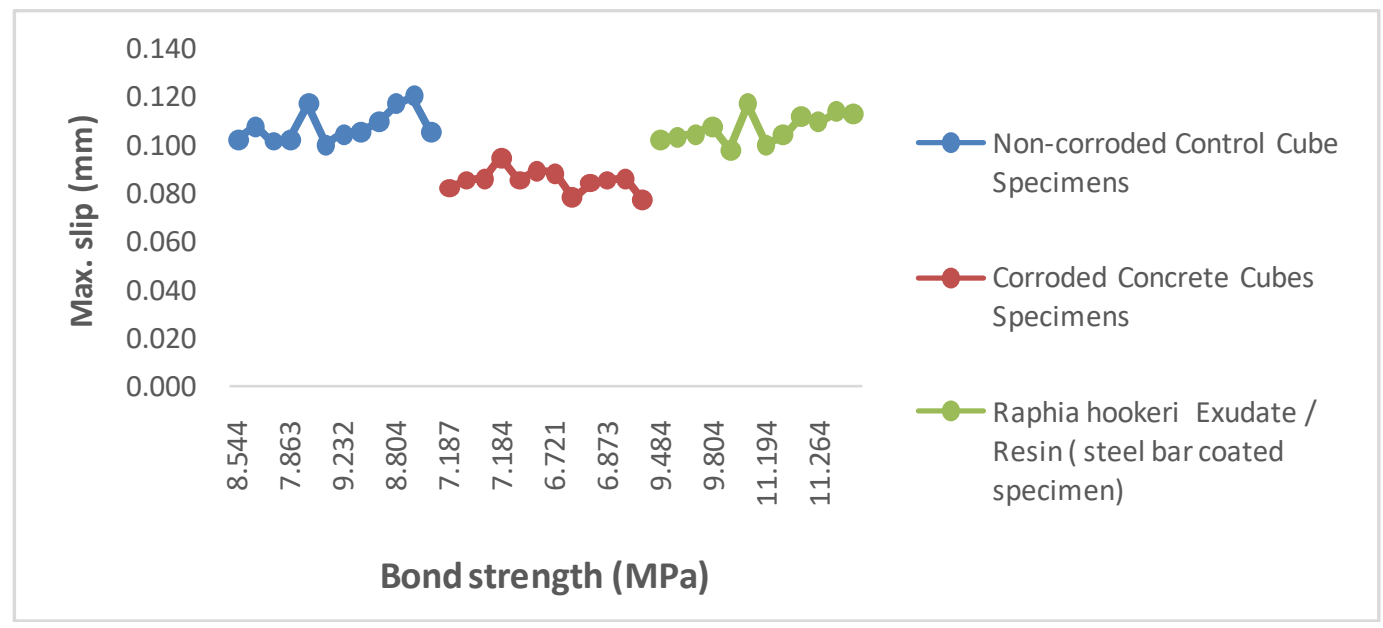

Figure 2: Bond Strengths versus Maximum Slip

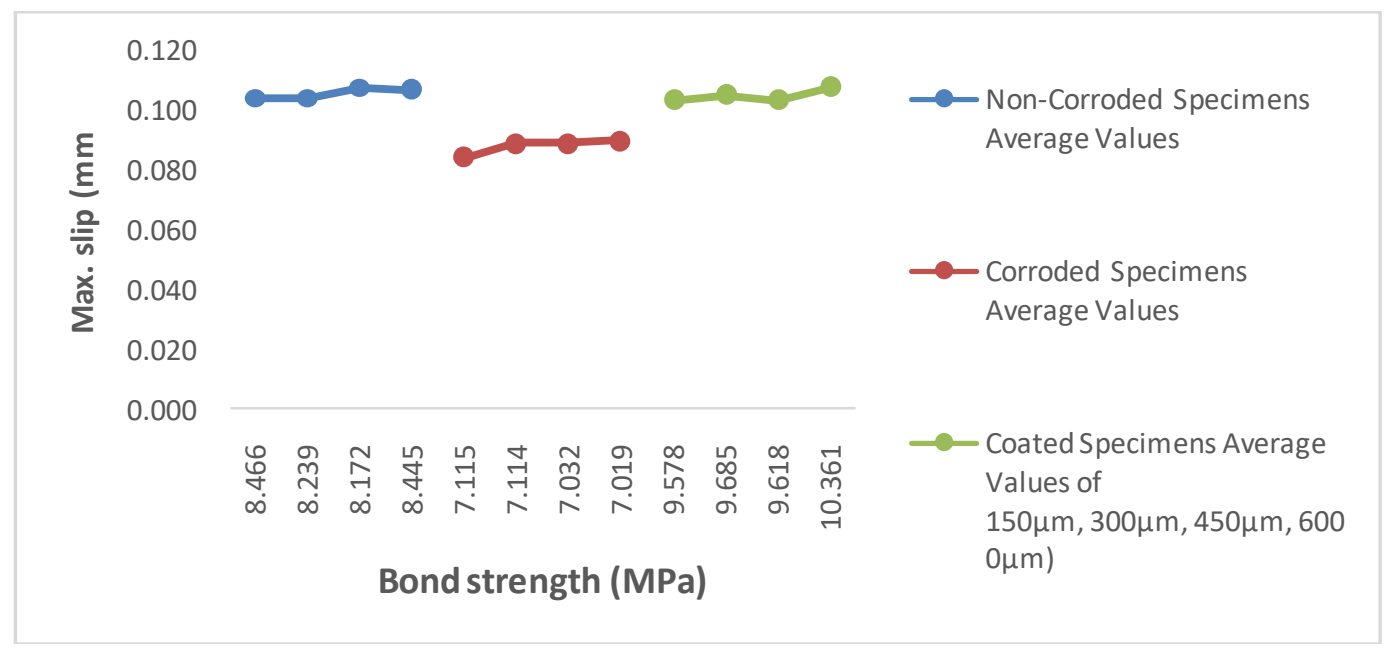

Figure 2a: Average Bond Strengths versus Maximum Slip 


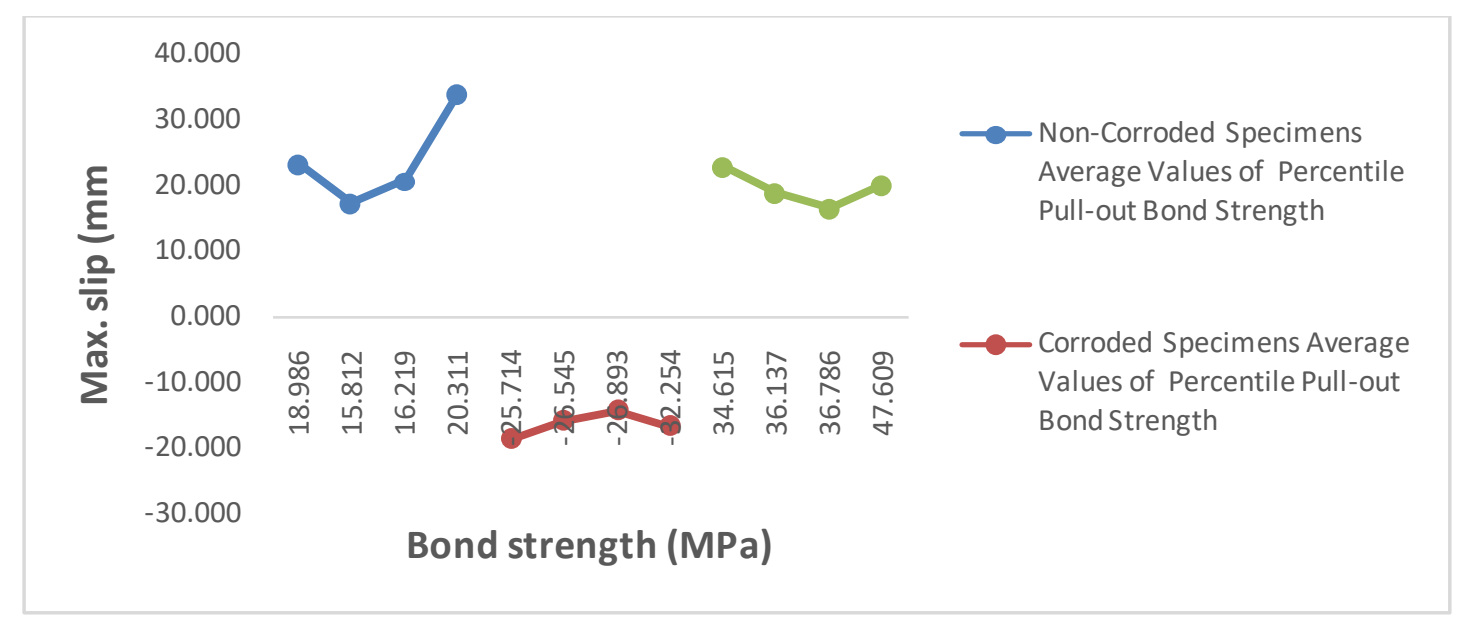

Figure 2b: Average Percentile Bond Strengths versus Maximum Slip

\subsection{Mechanical Properties of Reinforcing Bars}

The bond strength is mainly derived from the weak chemical bond between steel and hardened cement, but this strength is destroyed under small pressure. Once slippage occurs, friction will help bond. In smooth steel bars, friction is an important part of strength. Reinforcing steel bars with ribs under increased sliding connections mainly depend on the bearing or mechanical interlocking between the ribs and the surrounding concrete on the surface. This research introduced the application of exudates/resin to increase the slippage problem encountered by smooth reinforcing steel.

Data presented in table 3.1, 3.2 and 3.3 and collapsed into table 3.4 and further (finally) summarized into 3.5 accounted for the behavioral characteristics of the mechanical characteristics of controlled, uncoated (corroded) and coated concrete cube members subjected to failure state in Instron Universal Testing machine after corrosion accelerated induced process for 360 days and ascertained the periodic performances of the samples on an interval of 3 months respectively as stated in the tables and plotted in figures $1-6 \mathrm{~b}$. The controlled samples result are $100 \%$ values because they are pooled in tank of freshwater of compliance to (BS 3148) requirements.

The results are summarized into minimum and maximum values obtained from tables 3.4 and 3.5.

Nominal diameter steel bars of all samples are $100 \%$, and the minimum and maximum diameters of the steel bars measured before the test are within the range of $11.930 \mathrm{~mm}$ and $11.999 \mathrm{~mm}(0.240 \%$ and $0.250 \%)$. The diameter of the rebar uncoated samples (corroded) after corrosion are $11.881 \mathrm{~mm}$ and $11.881 \mathrm{~mm}(-1.081 \%$ and $-1.079 \%)$, after coated are $12.011 \mathrm{~mm}$ and $12.014 \mathrm{~mm}(1.091 \%$ and $1.098 \%)$, the uncoated coating (corrosion) is 0.049 $\mathrm{mm}$ and $0.047 \mathrm{~mm}(-14.634 \%$ and $-14.306 \%)$, the coating is $0.057 \mathrm{~mm}(16.951 \%$ and $17.143 \%)$.

The results of cross - sectional area for uncoated (corroded) are $0.049 \mathrm{~mm}$ and $0.043 \mathrm{~mm}$ ($5.318 \%$ and $-5.320 \%$ ), for coated are $0.052 \mathrm{~mm}$ and $0.058 \mathrm{~mm}(5.617 \%$ and $5.622 \%)$. The result for rebar weight before test for all samples are $0.560 \mathrm{Kg}$ and $0.592 \mathrm{Kg}(4.303 \%$ and $5.797 \%)$, weight after corrosion test for corroded are for $0.508 \mathrm{Kg}$ and $0.510 \mathrm{Kg}(-23.395 \%$ and $23.313 \%$ ), coated are $0.664 \mathrm{Kg}$ and $0.669 \mathrm{Kg}(30.169 \%$ and $30.539 \%)$ and weight loss /gain of steel are corroded $0.051 \mathrm{Kg}$ and $0.056 \mathrm{Kg}(-28.534 \%$ and $-30.608 \%)$ and coated values are $0.072 \mathrm{Kg}$ and $0.075 \mathrm{Kg}(39.927 \%$ and $44.108 \%)$.

From the results obtained and presented in the figures, the effect of corrosion on uncoated and coated reinforcing steel are enumerated, in figures 3 and $6 \mathrm{~b}$ on diameter of rebar, it can 
be seen that the diameter of uncoated decreased by maximum value of $-1.079 \%$ and coated increased by $1.098 \%$, for the cross - sectional area, corroded has maximum reduction value of $-5.320 \%$ and coated increased by $5.622 \%$, weight loss and gain are corroded $-28.534 \%$ decreased (loss) and coated $44.108 \%$ increase (gain). Indication as analyzed from the experimental work showed that the effect of corrosion on uncoated concrete cubes caused diameter and cross - sectional area reduction and weight decrease while coated concrete cubes have diameter and cross - sectional area increases and weight gain resulting from the varying thickness coated to reinforcing steel as stated in the studies of ([10][111][113],[115],[14]).

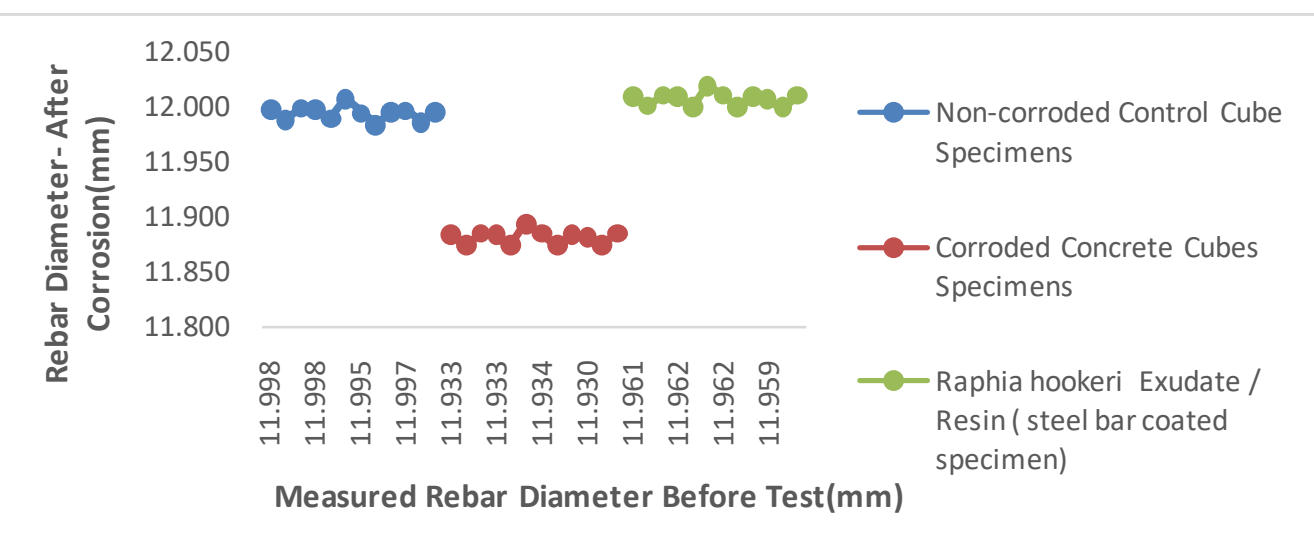

Figure 3: Measured (Rebar Diameter before Test vs Rebar Diameter- after Corrosion)

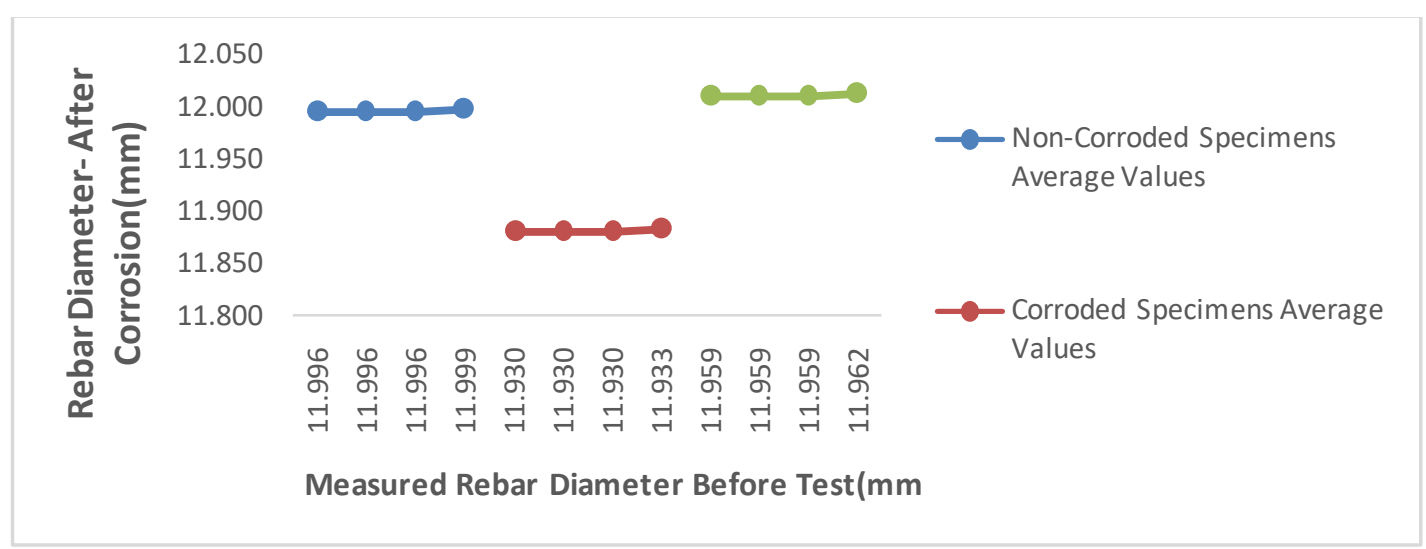

Figure 3a: Average Measured (Rebar Diameter before Test vs Rebar Diameter- after Corrosion)

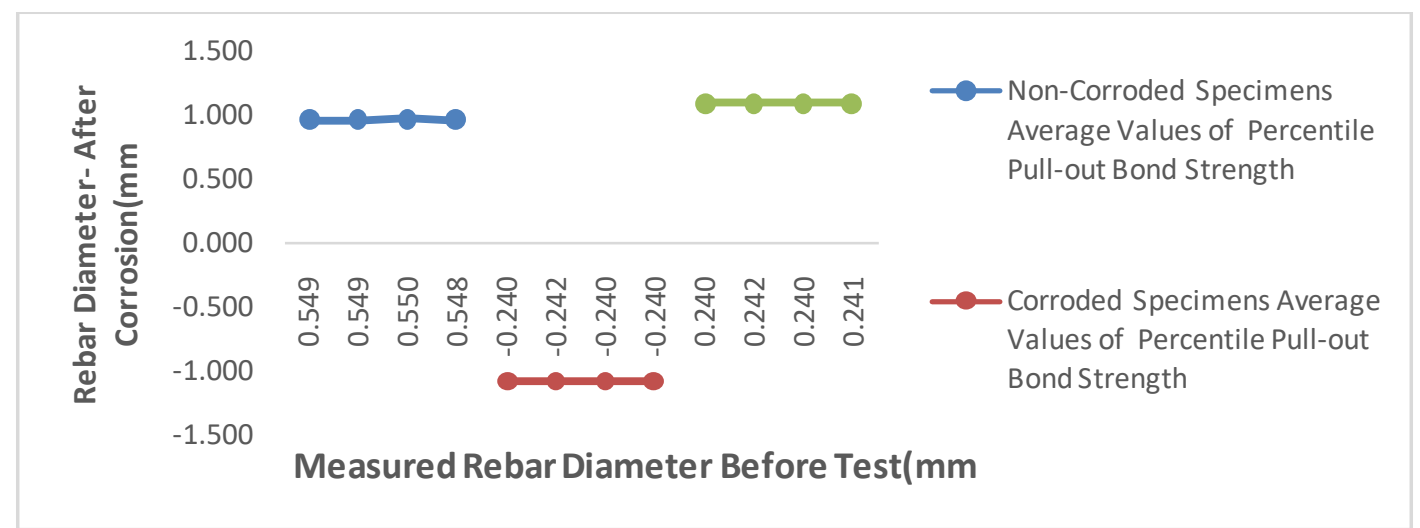

Figure 3b: Average Percentile Measured (Rebar Diameter before Test vs Rebar Diameter- after Corrosion) 


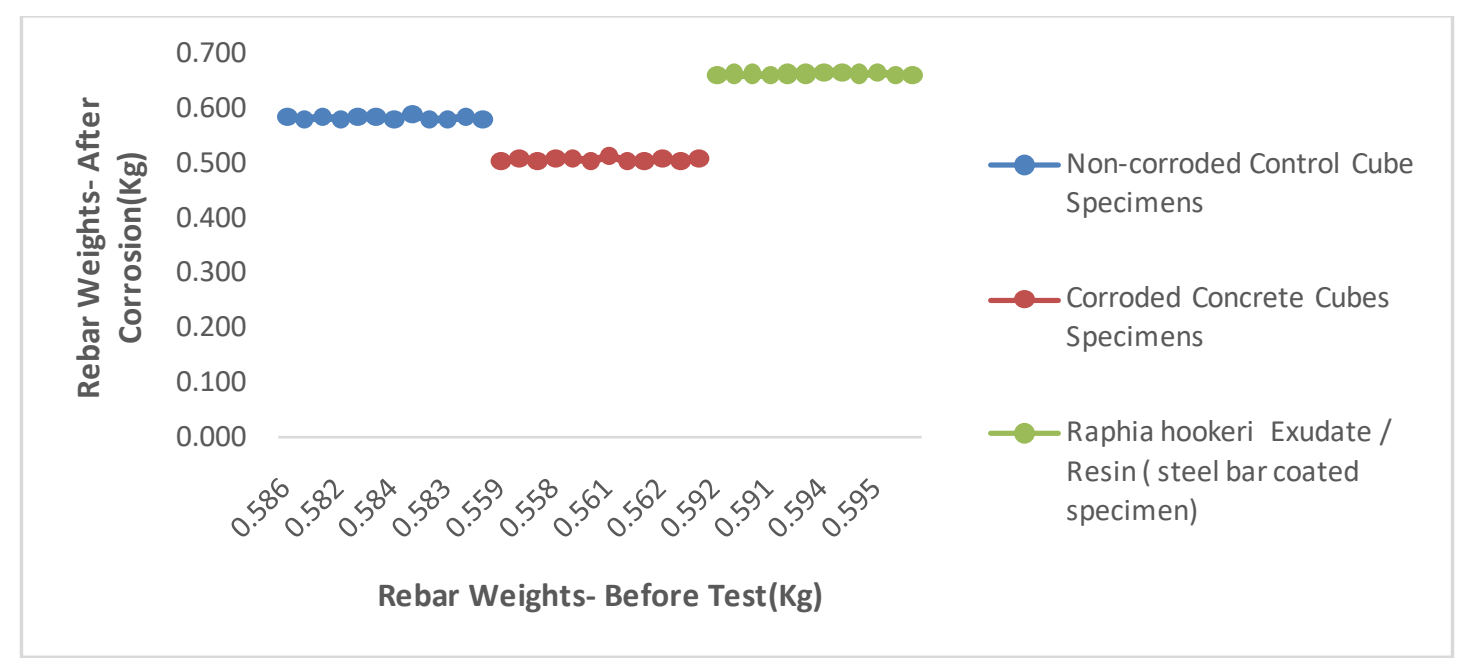

Figure 4: Rebar Diameter- after Corrosion versus Cross - Sectional Area Reduction/Increase

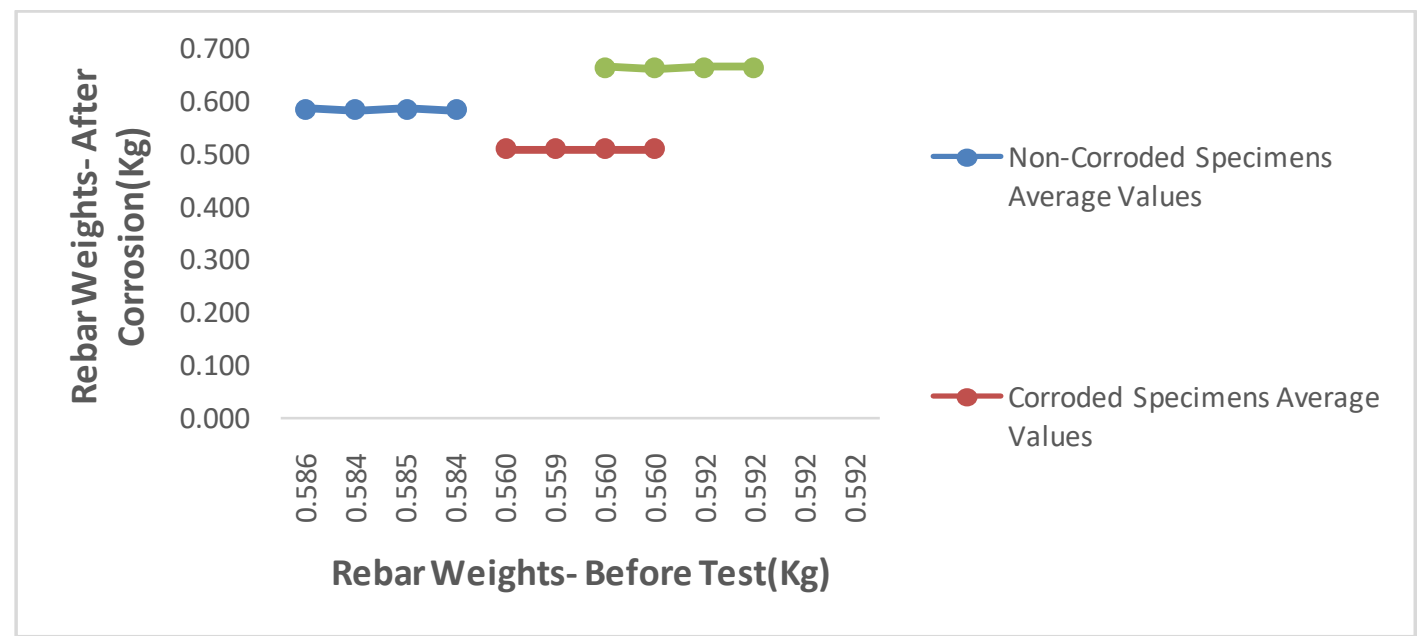

Figure 4a: Average Rebar Diameter- after Corrosion versus Cross - Sectional Area Reduction/Increase

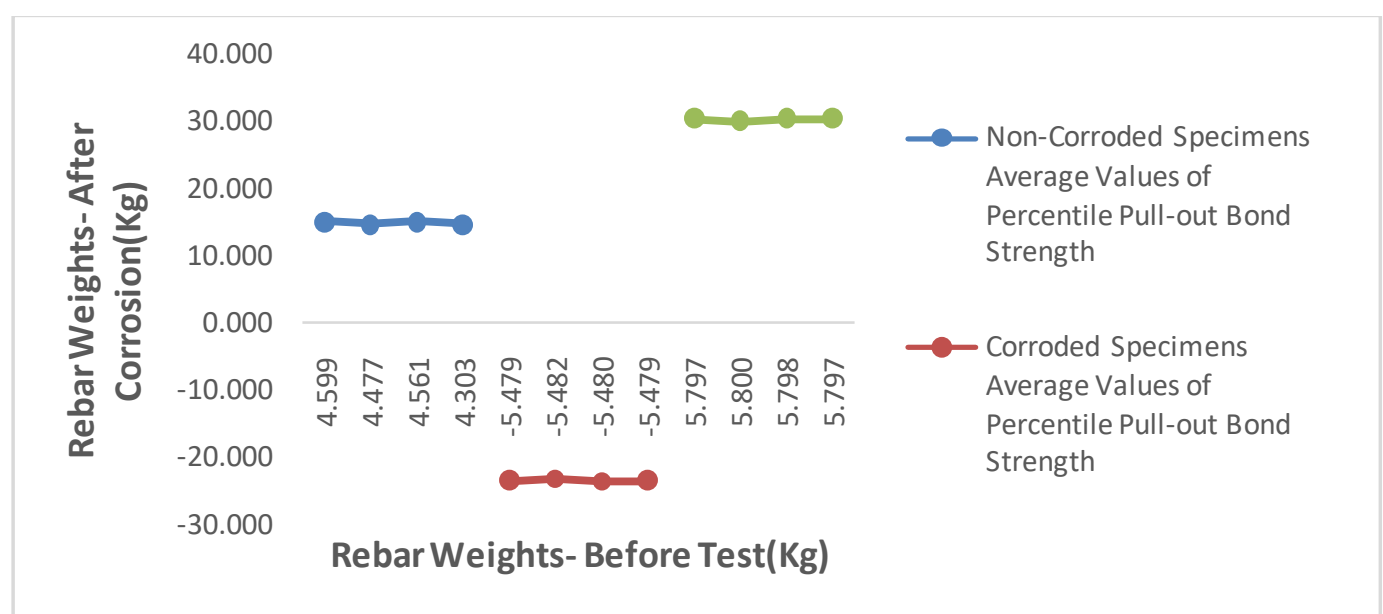

Figure 4b: Average percentile Rebar Diameter- after Corrosion versus Cross - sectional Area Reduction/Increase 


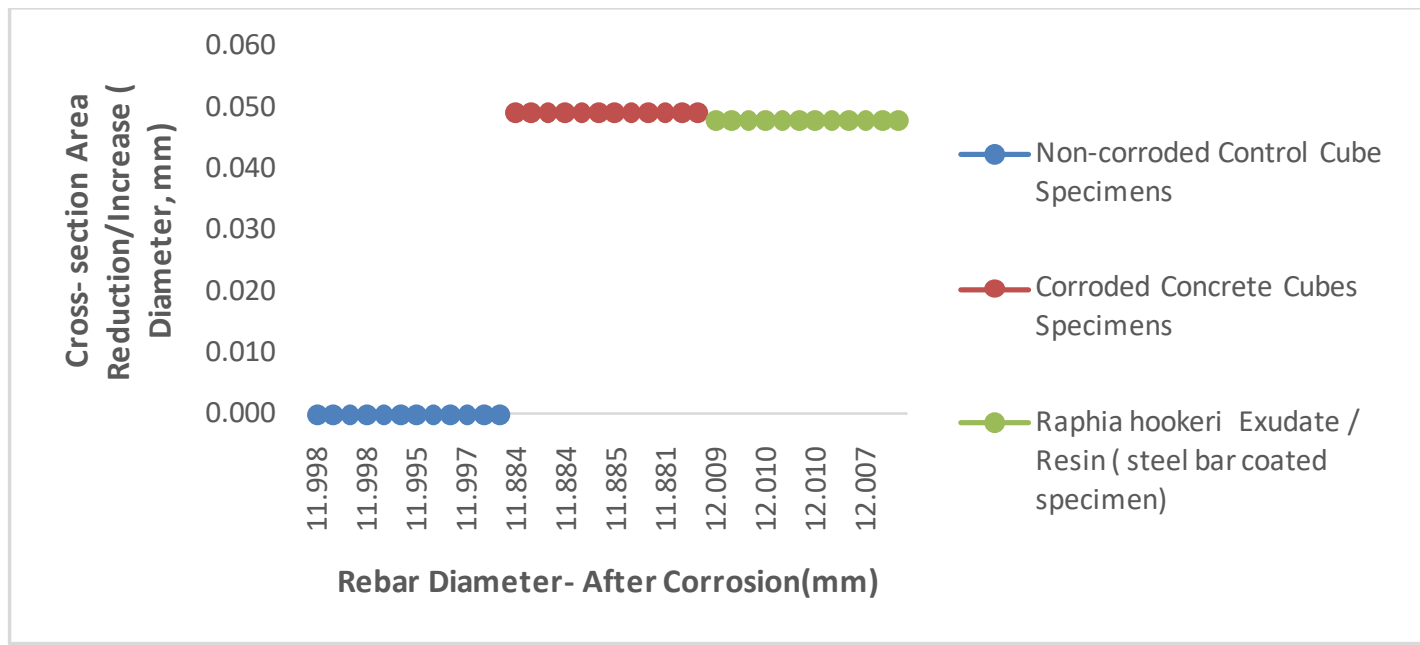

Figure 5: Rebar Weights- before Test versus Rebar Weights- after Corrosion

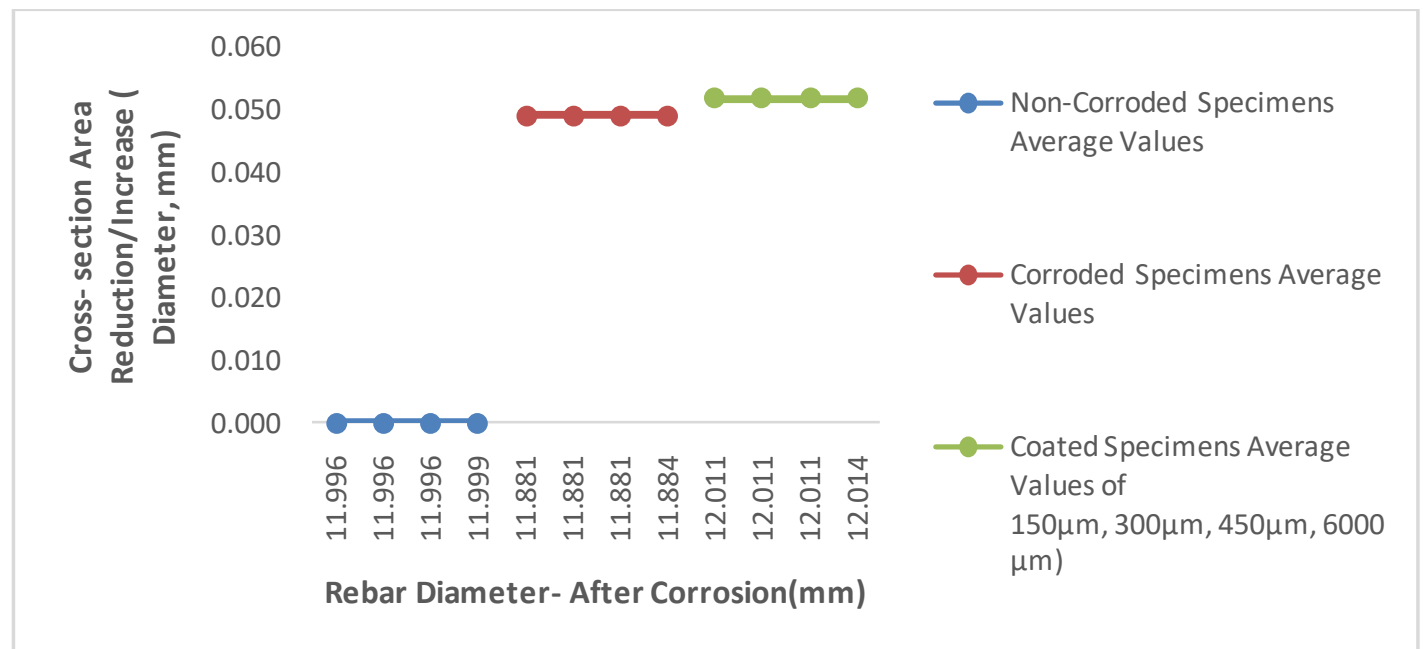

Figure 5a: Average Rebar Weights- before Test versus Rebar Weights- after Corrosion

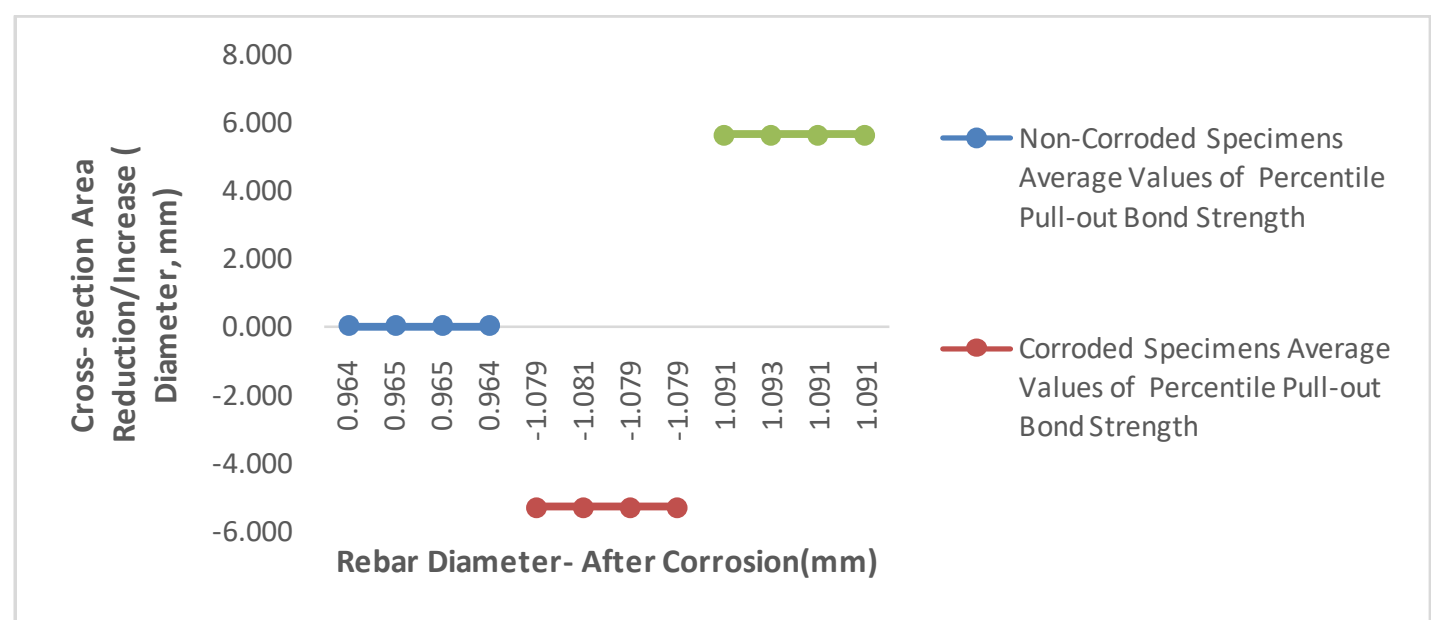

Figure 5b: Average Percentile Rebar Weights- before Test versus Rebar Weights- after Corrosion 


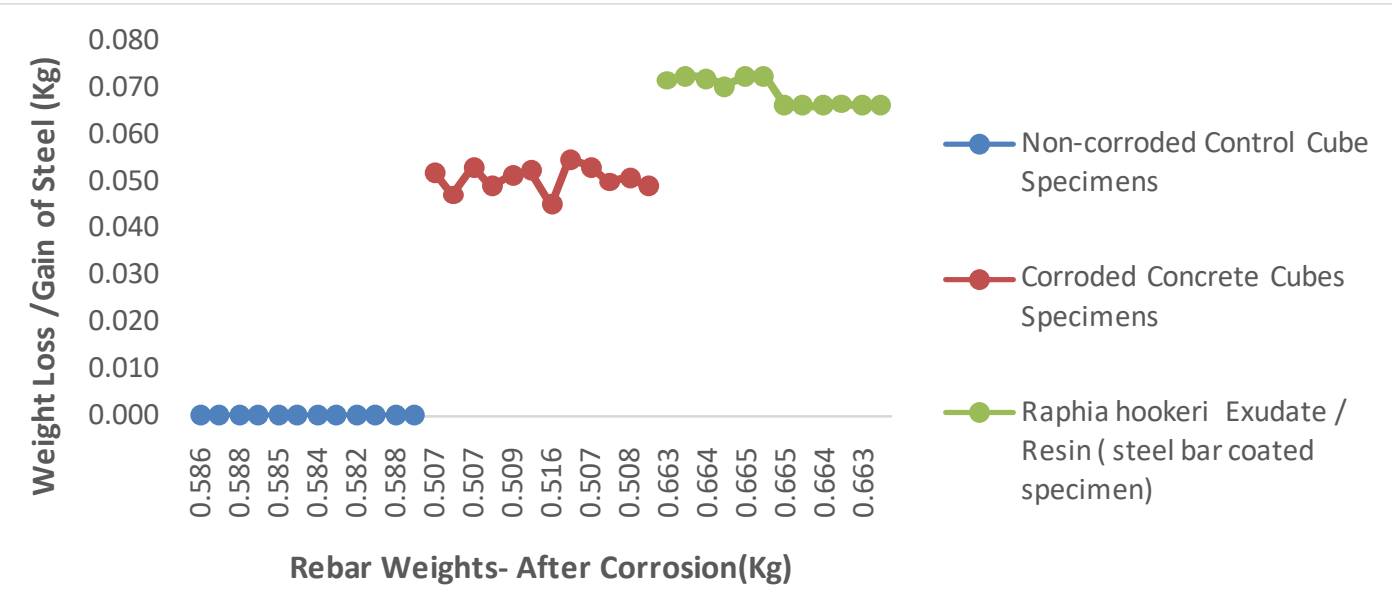

Figure 6: Rebar Weights- after Corrosion versus Weight Loss /Gain of Steel

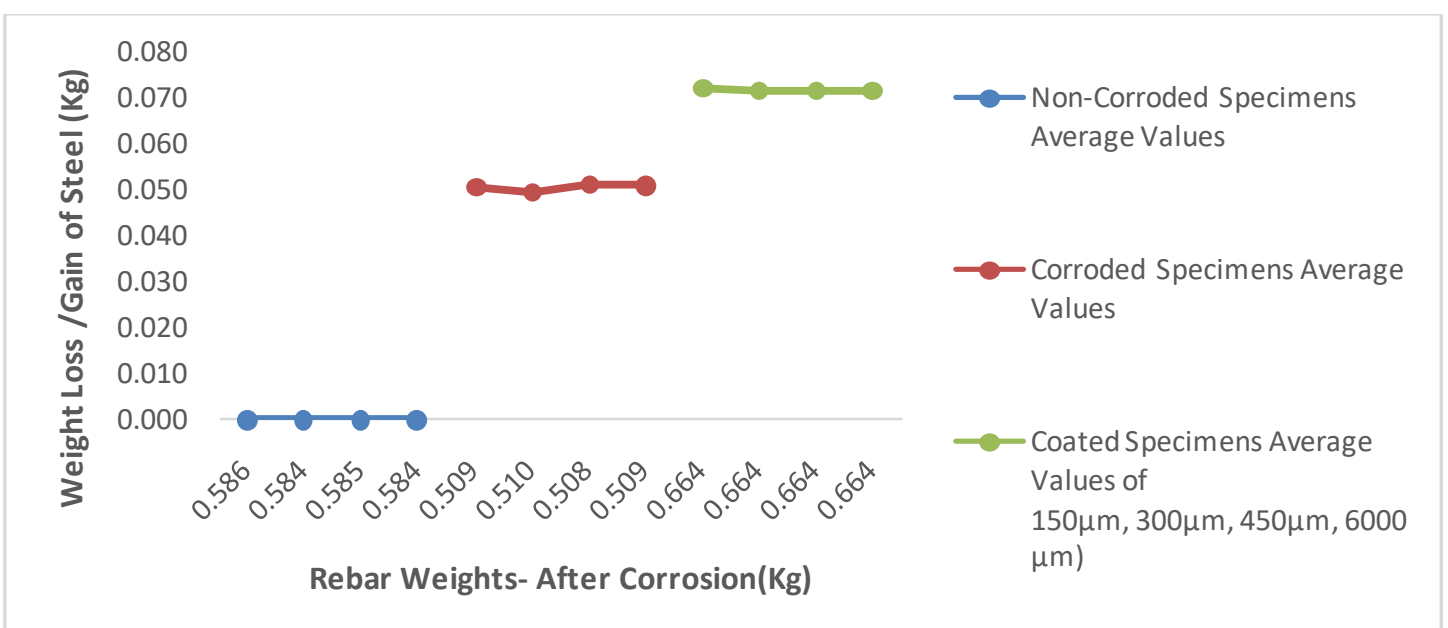

Figure 6a: Average Rebar Weights- after Corrosion versus Weight Loss /Gain of Steel

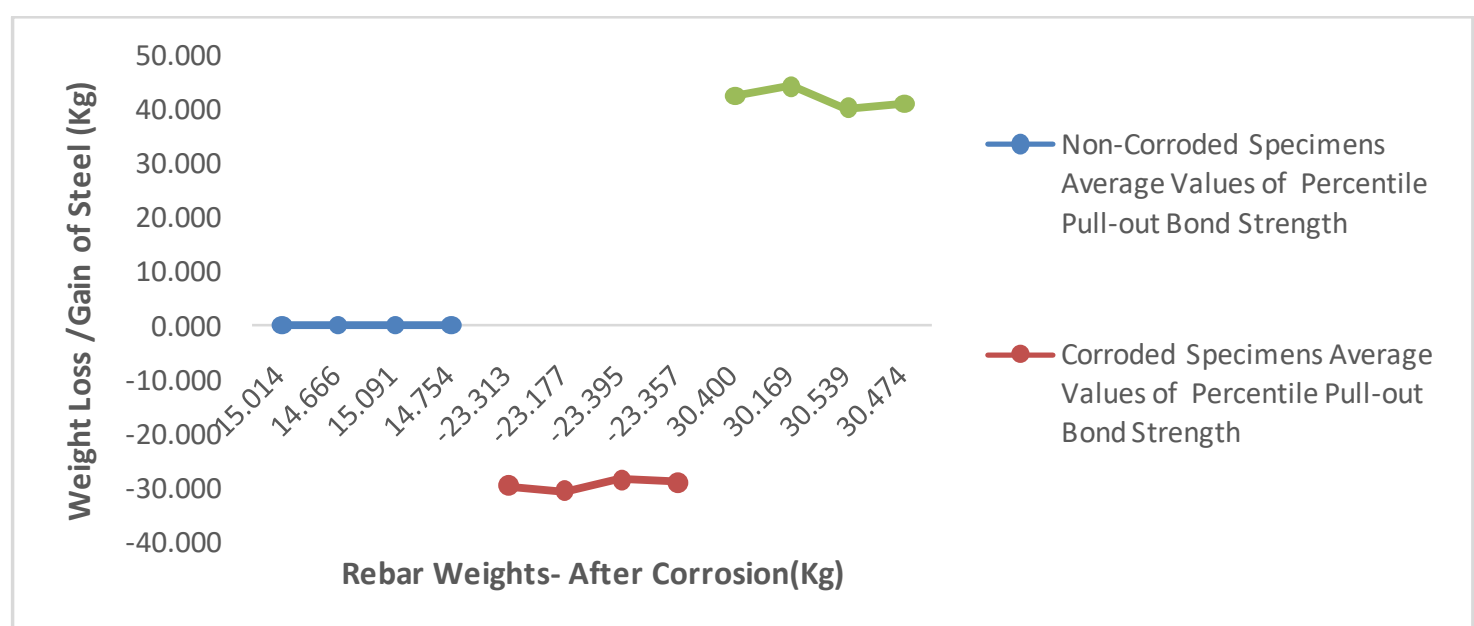

Figure 6b: Average percentile Rebar Weights- After Corrosion versus Weight Loss /Gain of Steel

\subsection{Comparison of Control, Corroded, and Coated Concrete Cube Members}

Comparatively, from the data in tables 3.1, 3.2 and 3.3 and in figures 3, 4,5 and 6 for 12 controlled samples pooled in a freshwater tank for 360 days, 12 uncoated and 12 coated 
pooled in $5 \%$ sodium chloride $(\mathrm{NaCl})$ aqueous solutions for 360 days ad described in 3.1 3.3 and summarized into tables $3.4-3.5$ and figures $3 a, 3 b, 4 a, 4 b, 5 a, 5 b, 6 a$ and $6 \mathrm{~b}$ for average and percentile values for failure bond loads, bond strength and maximum slip, cross sectional reduction / increase, diameter of rebar before /after corrosion, weight loss/gain. The results obtained in comparison showed that the failure bond load for controlled and coated maintained close range of values while corroded members yielded on lower load application, similar factors are on bond strength and maximum slip. On the mechanical properties of the reinforcing steel, the effect of corrosion on the reinforcing steel exhibited cross - section reduction on the diameter of the bar as compared to nominal diameter before test, weight loss also notice while and coated members posses cross -sectional area increased, diameter increase and weight increase as compared to nominal rebar, these increased resulted from the coating materials varying thicknesses. It can be concluded that the studied exudate/resin showed potency of inhibitory characteristics against corrosion attack and can be used as an inhibitor to corrosion.

\section{CONCLUSION}

In the experiment, the results obtained are drawn as:

i. The exudate/resin has an inhibitory effect on corrosion as its waterproofing resisted to corrosion penetration and attacks.

ii. The interaction between concrete and steel in the coated component is greater than that in the corroded samples

iii. The properties of the bonds in the coated and controlled components are greater than those in the corroded

iv. The lowest failure bond load, bond strength, and maximum slip were recorded in corroded member

v. The coating and control sample registered higher values of bond load and bond strength.

vi. Weight loss and reduction in cross section are mainly recorded in corroded coatings and controlled samples

\section{REFERENCE}

I. A. Almusallam, S. Ahmed, A. Gahtani and A. Rauf, Effect of reinforcement corrosion on bond strength, Construction and Building Materials, Vol. 10(2), pp. 123-129, 1996.

II. H. S. Lee, T. Noguchi and F. Tomosawa, Evaluation of the bond properties between concrete and reinforcement as a function of the degree of reinforcement corrosion, Cement and Concrete Research, Vol. 32(8), pp.1313-1318, 2002.

III. K. Lundgren, Modelling the effect of corrosion on bond in reinforced concrete, Magazine of Concrete Research, Vol. 54(3), pp. 165-173, 2002.

IV. A. Fang, K. Lundgren, L. Chen, and C. Zhu, Corrosion influence on bond in reinforced concrete," Cement and Concrete Research, 34, pp. 2159-2167, 2003.

V. P. K. Mehta and B. C. Gerwick, Cracking-Corrosion interaction in concrete exposed to marine environment, ACI Concrete International, 4, pp. 45-51, 1982.

VI. K. Charles, O. Ishmael,B. M. Akatah, P. P. Akpan., Comparative residual yield strength structural capacity of non-corroded, corroded and inhibited reinforcement embedded in reinforced concrete structure and exposed to severely medium, International Journal of Scientific and Engineering Research, Vol. 9(4), pp.11351149, 2018.

VII. K. Charles, T. T. W. Terence, O. Kelechi, I. S. Okabi, Investigation on comparative flexural residual yield strength capacity of uncoated and coated reinforcement 
embedded in concrete and exposed to corrosive medium, International Journal of Scientific \& Engineering Research, Vol. 9(4), pp.655-670, 2018.

VIII. A. W. Otunyo and K. Charles, Effect of corrosion on flexural residual strength and mid-span deflection of steel (coated with resins/exudates of trees) reinforced concrete beams under sodium chloride medium, European International Journal of Science and Technology, Vol. 6(7), pp.77-87, 2017.

IX. K. Charles, E. I. Ogunjiofor, L. P. Latam, Yield strength capacity of corrosion inhibited (resins / exudates) coated reinforcement embedded in reinforced concrete beam and accelerated in corrosive medium, European International Journal of Science and Technology, Vol. 7(3), pp.25-33, 2018.

X. K. Charles, Ogunjiofor, E. I., T. T.W.Terence, Pullout Bond Splitting Effects of Corroded And Inhibited Reinforcement In Corrosive Media, Journal of Multid isciplinary Engineering Science and Technology, Vol. 6(9), pp. 10747 -10753, 2019.

XI. T. T. W. Terence, K. Charles, E. Y. Branly, Bond Strength Characteristics of Reinforcements Embedded in Reinforced Concrete Structures in Corrosive Marine Environment, American Journal of Engineering Research, Vol.8(1)0, pp.128-134, 2019.

XII. D.S. Toscanini, T. E. Gede, K. Charles, Pullout Bond Failure Load of Corroded and Coated Members in Corrosive Media, International Journal of Advanced Scientific and Technical Research, Vol. 5(9), pp. 38 - 46, 2019.

XIII. T. E. Gede, K. Charles, B. Geofrey, Reinforcement Bond Strength Interface Behavior of Corroded and Coated in Concrete Members, European Academic Research, Vol.7(7), pp. 3399 - 3412, 2019.

XIV. K. Charles, A. T. John, C. O. John, Reinforcing Steel Mechanical Properties Influence on Bond Strength of Corroded and Coated Members in Concrete Structures, Global Scientific Journal, Vol. 7(9), pp. 1168 - 1178, 2019.

XV. E. N. Charles, K. Charles, T. T. W. Terence, Corrosion Degree on the Mechanical Properties of Reinforcing Steel Embedded in Concrete," Global Scientific Journal, Vol. 7 (10), pp. $688-696,2019$.

XVI. K. Charles, B. Geofrey, T. E. Gede, Corrosion Effect on Reinforcement Pull-Out Bond Strength Characteristics of Corroded and Coated Members in Concrete, American Journal of Sustainable Cities and Society Vol. 1(6), pp. 61 - 69, 2019

XVII. BS 882; - Specification for aggregates from natural sources for concrete, British Stand ards Institute. London, United Kingdom, 1992.

XVIII. BS EN 196-6; - Methods of Testing Cement Determination of fineness, British Stand ards Institute. London, United Kingdom, 2010.

XIX. BS 12390-5; 2005 - Testing Hardened Concrete: Flexural Strength Test of Specimens, British Stand ards Institute. London, United Kingdom, 2005.

XX. BS 12390-5; 2005 - Testing Hardened Concrete: Flexural Strength Test of Specimens, British Stand ards Institute. London, United Kingdom, 2005.

XXI. ACI Committee 408R., Bond and development of straight reinforcing bars in tension, American Concrete Institute, Detroit, US A, 2003 